Çukurova Üniversitesi Mühendislik Fakültesi Dergisi, 36(3), ss. 701-708, Eylül 2021

Cukurova University Journal of the Faculty of Engineering, 36(3), pp. 701-708, September 2021

\title{
Yapay Sinir Ağları Yöntemi ile Adıyaman Gölbaşı-Adıyaman Merkez Arasının Heyelan Duyarlılık Değerlendirmesi
}

\author{
Berna TANRIVERDi' ${ }^{*}$, Osman ORHAN ${ }^{1}$, Senem TEKIN ${ }^{2}$ \\ ${ }^{1}$ Mersin Üniversitesi, Fen Bilimleri Enstitüsü, Uzaktan Algılama ve Coğrafi Bilgi Sistemleri \\ Anabilim Dal, Mersin \\ ${ }^{2}$ Adryaman Üniversitesi, Teknik Bilimler Meslek Yüksekokulu, Madencilik ve Maden Çıkarım \\ Bölümü, Adlyaman
}

Geliş tarihi: 28.06.2021 Kabul tarihi: 13.09.2021

\section{$\ddot{O} z$}

Bu çalışmada, Gölbaşı-Merkez (Adıyaman) arasında kalan yaklaşı $1200 \mathrm{~km}^{2}$ lik bölgede yapay sinir ağları yöntemi ile heyelan duyarlılık değerlendirmesi yapılmıştır. Çalışma alanında 177 heyelan bulunmakta olup, $79,85 \mathrm{~km}^{2}$ lik alana sahiptir. Duyarlılık değerlendirmesi için yükseklik, jeoloji, yamaç eğimi, pürüzlülük, topoğrafik nemlilik indeksi parametreleri heyelan hazırlayıcı faktörler olarak kullanılmıştır. Çalışma alanından elde edilen veri seti rastgele seçim yöntemiyle \%80'i analiz, \%10'u test ve \%10'u doğrulama verisi olmak üzere üçe ayrılmıştır. Elde edilen duyarlılık haritası çok düşük ile çok yüksek arasında 5 sınıfta değerlendirilmiştir. Elde edilen heyelan duyarlılık haritasına göre; çalışma alanının yaklaşık \%30'u, mevcut heyelanların ise \%78,4'ü yüksek ve çok yüksek duyarlı alanlarda yer almaktadır. Elde edilen heyelan duyarlılık haritasının doğruluğu alıcı işletim karakteristik eğrisi ve eğri altında kalan alan ile değerlendirilmiş olup 0,84 olarak hesaplanmıştır $\mathrm{Bu}$ değer kurulan modelin doğruluğunun yüksek bir değere sahip olduğunu göstermektedir.

Anahtar kelimeler: Heyelan, Yapay sinir ağları, Heyelan duyarlılık değerlendirmesi

\section{Landslide Susceptibility Assessment Between Adıyaman Gölbaşı-Adıyaman Center with Artificial Neural Network Methods}

\begin{abstract}
In this study, landslide susceptibility assessment was carried out using artificial neural networks in an area of approximately $1200 \mathrm{~km}^{2}$ between Gölbaşı and Center (Adıyaman). There are 177 landslides in the study area and the area cover $79.85 \mathrm{~km}^{2}$. Digital elevation model, geology, slope, roughness index, topographic position index (TPI) parameters were used as factors that controlling landslides in susceptibility evaluations. The data set belonging to the study area was divided into three as $\% 80$ analysis, \%10 test and \%10 validation data by the random selection method. The susceptibility map obtained was evaluated in 5 classes, from very low to very high. According to the susceptibility map; approximately $\% 30$ of the study area and \%78.4 of landslides are located in high and very sensitive areas. The accuracy of the landslide susceptibility map obtained was evaluated with the receiver operating characteristic curve and the area under the curve and it was calculated as 0.84 . This value shows that the accuracy of the established model has a high value.
\end{abstract}

Keywords: Landslide, Artificial neural network, Landslide susceptibility assesment

*Sorumlu yazar (Corresponding author): Berna TANRIVERDİ, bernatnrvrd@ gmail.com 


\section{GíRiş}

Afet genel anlamda, bir toplumu veya çevreyi olumsuz olarak etkileyen, aniden gelişen, doğa veya insan kaynaklı olaylar olarak tanımlanmaktadır. Heyelanlar; dünyada olduğu gibi ülkemizde de en çok can ve mal kaybına sebep olan doğal afetlerden biridir. Özellikle son yıllarda gelişen afetlerde, afet sonrası müdahale ve iyileştirme çalışmaları yürütülmektedir. Fakat çalışmalar afet sonrası döneme yönelik olduğundan, afetin yol açtığı kayıpların azaltılmasında etkisi bulunmamaktadır. Özellikle gelişen teknoloji ve yöntemler yardımıyla, heyelan envanter haritaları ve heyelana sebep olan çevresel değişkenlerin birlikte değerlendirilmesi ile elde edilen heyelan duyarlılık değerlendirmeleri, heyelan afetinin çalışılan bölgede gelecekte nerelerde meydana geleceğine yönelik 1 şık tutmaktadır. Dolayısıyla, heyelan duyarlılık çalışmaları heyelanlardan kaynaklı afet zararlarının azaltılmasına yönelik faydalar sunmaktadır [1-2]. Heyelanları hazırlayıcı faktörler mevcut arazi koşullarına bağlı olarak, jeoloji/litoloji haritası, sayısal yükseklik modeli ve türev haritaları (yamaç eğimi, yamaç eğrisellikleri, pürüzlülük vb.) ile arazi kullanımı/arazi örtüsü modellerinden oluşmaktadır. Geçtiğimiz yıllarda, heyelan duyarlılık değerlendirmesinde CBS teknikleri kullanılarak farklı araştırmalar yapılmıştır [3-9]. $\mathrm{Bu}$ anlamda arazi kullanım planlamasi, sürdürülebilir kalkınma sürecinin merkezinde yer almakta olup, doğal afetlere yönelik yapılması planlanan planlama çalışmalarda doğal olası tehlikelerin göz önünde bulundurulması gerekmektedir [9]. Gerek arazi yönetimi gerek afet yönetimi konusunda sürdürülebilir bir planlama açısından ülkemizde sık rastlanan doğal afet olaylarından heyelanların mekansal olarak nerede gerçekleşebileceğini gösteren duyarlılık haritaları, bölgesel ölçekli planlama ve heyelan zarar azaltma çalışmalarının önemli aşamalarından birini oluşturmaktadır [9-11]. Heyelan duyarlılık haritalarının hazırlanması; heyelanların tipi, dağılımı ve envanter haritasının güvenilirliği başta olmak üzere, heyelanları hazırlayıcı uygun çevresel değişkenlerin göz önünde bulundurulması gibi birçok faktöre bağlıdır [9].
Bu çalışmada ise, Adıyaman Gölbaşı - Adıyaman Merkez arasında CBS tabanlı olmak üzere bölgede meydana gelebilecek heyelanlar için yapay sinir ağları yöntemi kullanılarak duyarlılık çalışması gerçekleştirilmiştir. Heyelan duyarlılık haritasının güvenilirliği önceden gerçekleştiği bilinen heyelan envanterleri ile modellenmiş ve karşılaştırılarak kontrol edilmiştir.

\section{2. ÇALIŞMA ALANI KULLANILAN VERILER}

VE

$\mathrm{Bu}$ çalışma; Adıyaman iline bağlı Gölbaşı ve Merkez ilçeleri arasında kalan $1200 \quad \mathrm{~km}^{2}$ 'lik bölgede gerçekleştirilmiştir (Şekil 1). Çalışma alanının iklimi yer yer karasal iklim karakteristiği gösterse de çoğunlukla Akdeniz iklim özelliğini kapsamaktadır. Yıllık ortalama yağışlı gün sayısı 88,8 iken yıllık ortalama yağış miktarı 720 mm'dir. En fazla yağış Aralık-Ocak ayında; en az yağış ise Temmuz-Ağustos aylarında gerçekleşmektedir. Ortalama yıllık sicaklık ise $17,2{ }^{\circ} \mathrm{C}$ 'dir. En yüksek sıcaklık Temmuz-Ağustos; en düşük sıcaklıklar ise Ocak-Şubat aylarında meydana gelir [12].

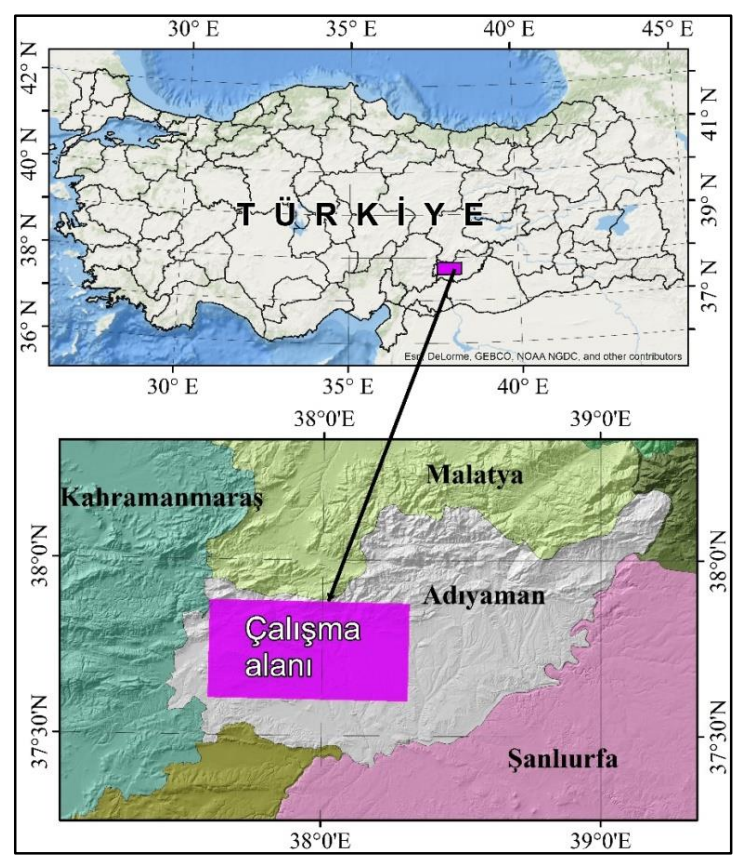

Şekil 1. Çalışma alanı yer bulduru haritası 


\subsection{Heyelanları Değişkenler \\ Hazırlayıcı Çevresel}

Çalışmada heyelanları hazırlayıcı faktörler olarak başta jeoloji haritası olmak üzere (Şekil 2), İkincil faktörler olarak ASTER Sayısal Yüskeklik Modeli (ASTER GDEM) (Global Digital Elevation Model V003) (NASA/METI/AIST/Japan Spacesystems and U.S./Japan ASTER Science Team 2019) (Aster GDEM)'den elde edilen $28 \mathrm{~m}$ yersel çözünürlüğe sahip sayısal yükseklik modeli (SYM) ve türev haritaları olan yamaç eğimi, yamaç yönelimi, pürüzlülük indeksi, topoğrafik nemlilik indeksi parametreleri kullanılmıştır. Çalışma alanında 177 heyelan bulunmakta olup alansal olarak 79,85 km²'lik alansal büyüklüğe sahiptir (Şekil 3). Jeolojik olarak, Sayısal yükseklik Ekay zonunun güneyinde bulunan çalışma alanındaki birimler, üst alloktan seri tarafından tektonik olarak üzerlenmektedir. Üst Kretase-Miyosen zaman aralığında Arap kıtasının kuzeyindeki farklı tektonik birliklerin birleşmesi ile farklı naplar bölgede gelişmiştir. $\mathrm{Bu}$ nap paketleri Eosen döneminin sonlarında okyanusun gerilemesiyle birlikte Arap platformu ile çarpışmıştır. Naplar ile Arap platformu arasındaki gerilimler sonucu bölgede biriken deformasyonlara bağlı olarak doğu-batı gidişi ters fay ve şaryaj dilimlerinden oluşan ekay zonu gelişmiştir. Çalışma alanı ve civarında temelde Koçali Karmaşığı yer almaktadır. Birimin üzerine uyumsuzlukla otokton birimler yüzeylemektedir. Jura-Alt Kretase yaşlı Koçali karmaşı ğı, Koçali ofiyoliti ile volkanosedimanter özellikteki Koçali melanjını kapsamaktadır [13]. Otokton birimler olarak; Katel, Antak, Besni, Arpalı, Germav, Midyat, Hoya, Zeytin formasyonları, Yavuzeli bazaltı ve alüvyonlardan oluşmaktadır.

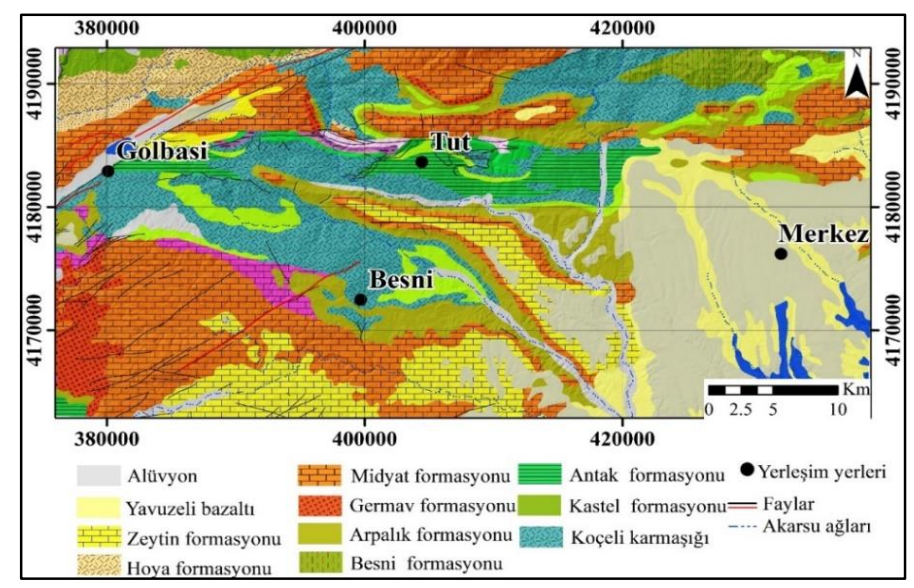

Şekil 2. Çalışma alanına ait jeoloji haritası [14]

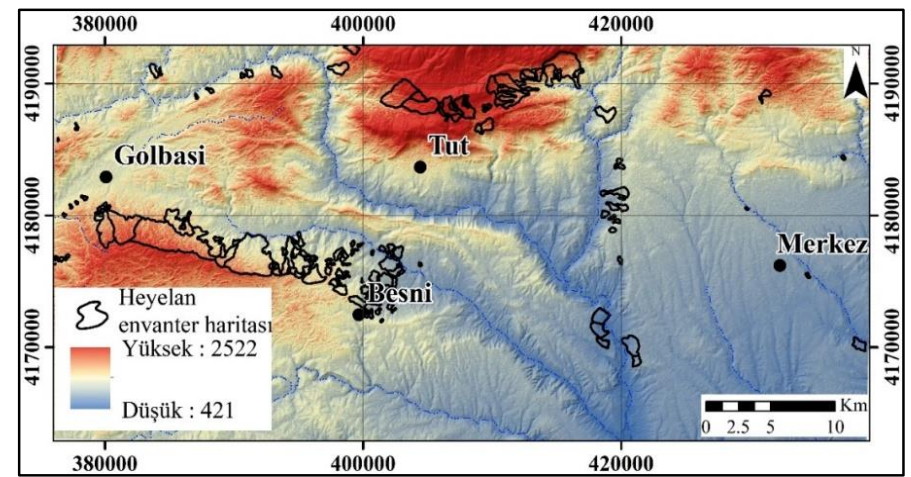

Şekil 3. Sayısal yükseklik modeli ve çalışma alanına ait heyelan envanter haritası [15] 
Sayısal yükseklik modeli kullanılarak üretilen yamaç eğimi, yamaç eğriselliği, topoğrafik nemlilik indeksi (TPI) ve pürüzlülük indeks parametreleri raster tabanlı 100 metre yersel çözünürlükte çalışmada kullanılmıştır (Şekil 4). Eğim, lokasyonu belli iki nokta arasında ki düşey mesafenin yatay mesafeye oranının tanjantı ile hesaplanmaktadır. Özellikle yamaçların iç kesimlerde yüksek değerlere ulaştığı görülmektedir (Şekil 4a). Yamaç eğriselliği parametresi, yüzeysel su akış hızı ve yüzey malzemesinin yamaç boyunca taşınımı ile ilgili parametrelerden biri olup, çalışılan bölgede eğim değişim oranını ifade etmek için kullanılmaktadır (Şekil 4b). İç bükey ve

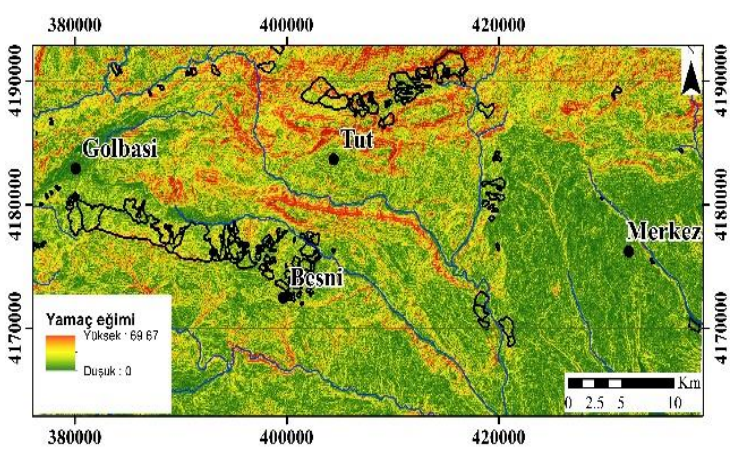

(a)

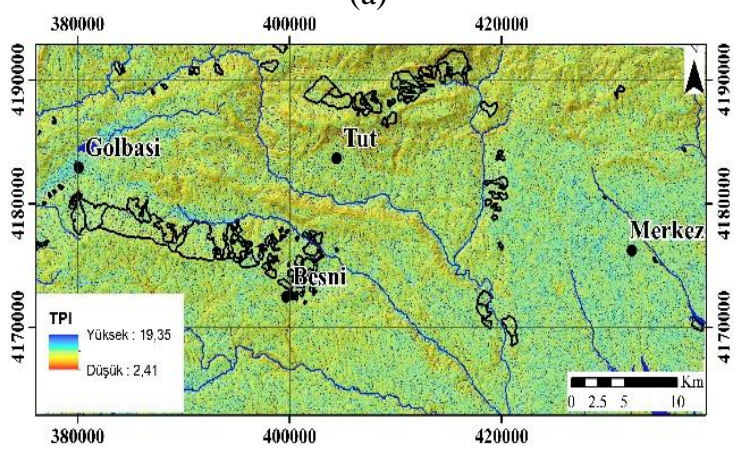

(c) dıș bükey yamaç şekilleri (Şekil 4c) hidrolojik akış durumunu kontrol etmesi bakımında heyelan duyarlılık değerlendirmelerinde sıklıkla kullanılan parametrelerden birini oluşturmaktadır. Topografik nemlilik indeksi (TWI) yüzeysel akış potansiyeline sahip bölgelelerin belirlenmesinde kullanılan önemli değişkenlerden biridir. Pürüzlülük indeksi parametresi (Şekil 4d), arazinin morfolojik özelliklerinin belirlenmesinde, sediment taşıma modellemesi, ekolojik çalışmalar, arazi şekillerinin jeomorfolojik değerlendirmesi ve doğal afetler ile ilgili birçok farklı çalışmada kullanılan parametrelerden biridir.

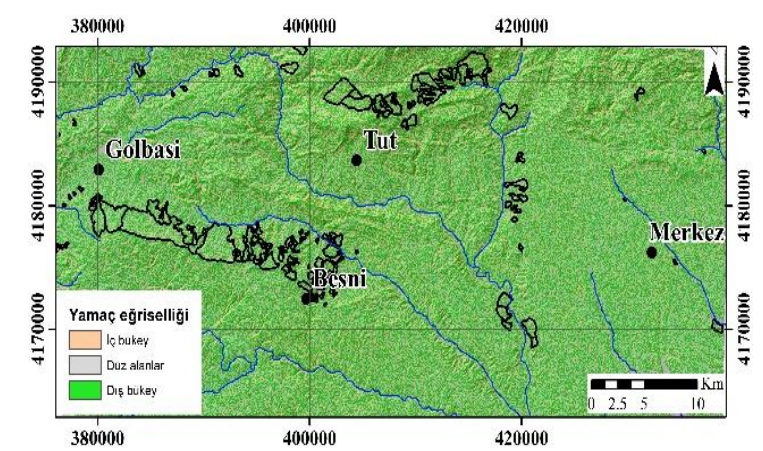

(b)

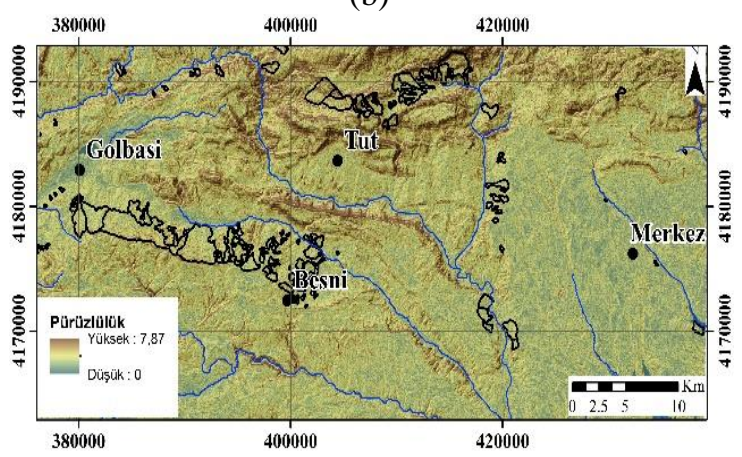

(d)

Şekil 4. Çalışma alanına ait yamaç eğimi, yamaç eğriselliği (b), topoğrafik nemlilik indeksi (TWI) (c), pürüzlülük indeksi (d) haritaları

Heyelanları hazırlayıcı çevresel değişkenlere ait detaylı istatistiksel veriler Şekil 5a, b'de verilmiştir. Buna göre çalışma alanının geneli için pürüzlülük, yamaç eğimi, sayısal yükseklik modeli (SYM) ve topoğrafik pozisyon indeksi (TPI) parametreleri sırasılyla en düşük $0,0.421,3.24$ değere sahipken en yüksek 11.40, 51.22, 2522 ve
17,60 değerlere sahiptir. Heyelanlı alanlarda ise değerler pürüzlülük, yamaç eğimi, sayısal yükseklik (SYM) ve topoğrafik nemlilik indeksi (TWI) parametreleri sırasıyla en düşük 0,58, 0,481, 3,49 değere sahipken en yüksek 10,84, 44,96, 2058 ve 14,10 değerlere sahiptir. 


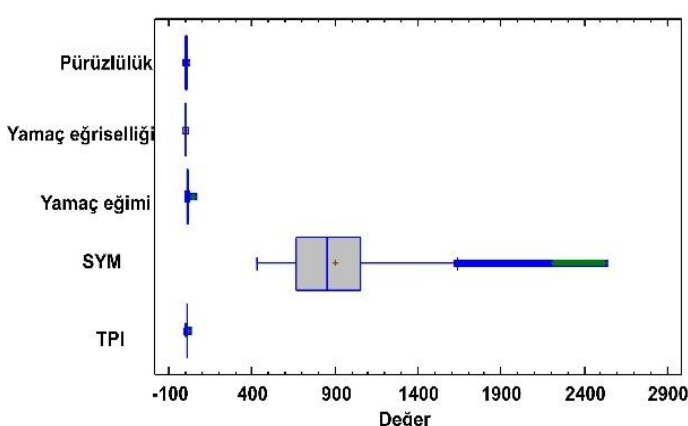

(a)

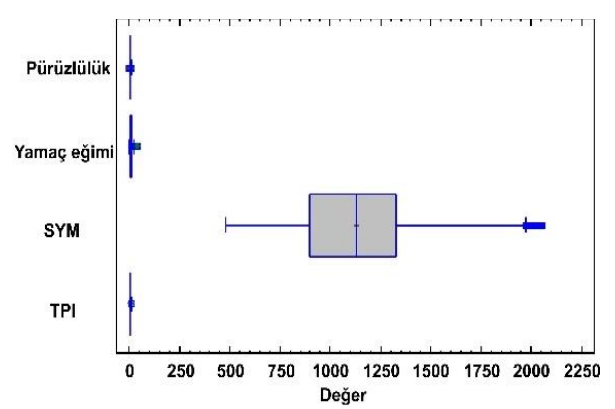

(b)

Şekil 5. Pürüzlülük, yamaç eğriselliği, yamaç eğimi, sayısal yükseklik modeli topoğrafik nemlilik indeksi parametrelerinin çalışma alanı (a) ve heyelanlı alanlara (b) ait dağılım istatistikleri

Heyelan duyarlılık değerlendirmeleri genel olarak niceliksel ve niteliksel olmak üzere değerlendirilmekte olup her ikisinde de alt yöntemler bulunmaktadır [16]. Niceliksel yöntemlerden veri güdümlü yöntemlerden literatürlerde tercih edilme oranı yüksek olan yapay sinir ağları (YSA) kullanılarak bu çalışma gerçekleştirilmiştir. YSA paralel olarak bağlantılı olan çok sayıda basit elemanın biyolojik sinir sistemi benzerleriyle etkileşim kuran, matematiksel modelleme yöntemler bütünü olarak tanımlanmaktadır [17]. Geri yayılma eğitim algoritması, en sık kullanılan sinir ağı yöntemi olması sebebiyle bu çalışmada da tercih edilmiştir. Geri yayılma eğitim algoritması, bir dizi ilişkili veriyi kullanılarak eğitim algoritması içerir. Girdi (heyelanları hazırlayıcı çevresel değişkenler) ve çıktı (heyelanlı bölgeler) değerleri, belirlenen gizli katman sayıları ile siyah kutu denilen arka planda işlenir ve sonuç olasılık değerler üretilir. Öğrenme algoritması, çok katmanlı bir sinir ağıdır. Sinir ağlarını kullanmanın iki aşaması vardır: ilk aşama iç ağırlıkların hesaplandığı eğitim aşaması ikinci aşama ise sınıflandırma aşamasıdır. Tipik olarak, geri yayılma algoritması, ağın istenen ve gerçek çıktı değerleri arasında hedeflenen bir minimum hata elde edilene kadar ağı eğitir. Eğitim tamamlandıktan sonra, ağ tüm veriler için bir sınıflandırma oluşturmak için ileri beslemeli bir yapı olarak kullanılır. Bir sinir ağı, birbirine bağlı birkaç düğümden oluşur. Her bir düğüm basit bir işlem elemanıdır diğer düğümlerden aldığı ağırlıklı girdilere tepki verir. Bu düğümlerin düzenlenmesi, ağ mimarisi olarak belirtilir (Şekil 6). Alıcı düğüm, önceki katmanda bağlı olduğu tüm düğümlerden gelen ağırlıklı sinyalleri toplar.

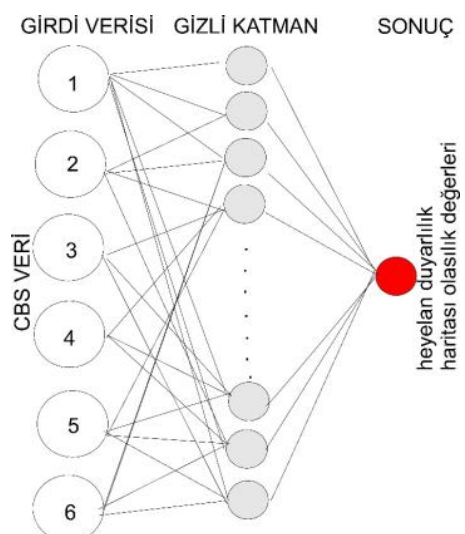

Şekil 6. Yapay sinir ağı yapısı

\section{BULGULAR}

Gölbaşı (Adıyaman)-Merkez (Adıyaman) arasında yapılan heyelan duyarlılık değerlendirmesi YSA yöntemi ile gerçekleştirilmiştir. Çalışmada 6 değişken $100 \mathrm{~m}$ yersel çözünürlüğe göre hazırlanmıştır. Karsoliya (2012) [18] tarafından önerilen giriş katman sayısının üçte ikisi ile iki katı arasında değişen gizli katman sayıları denenmiş ve en iyi sonuç elde edilen 15 gizli katman kullanılarak duyarlılık haritası oluşturulmuştur. Çalışma alanına ait veri seti rastgele seçim yöntemiyle $\% 80$ analiz, $\% 10$ test ve $\% 10$ doğrulama verisi olmak üzere üçe ayrılmıştır. Heyelan duyarlılık haritası çok düşük, düşük, orta, 
yüksek ve çok yüksek olmak üzere eşit aralıklarla beş sınıfta değerlendirilmiştir (Şekil 7).

Elde edilen duyarlılık haritasına göre; çalışma alanının yaklaşık \%30'u heyelanların ise \%78,4'ü yüksek ve çok yüksek duyarlı alanlarda yer almaktadır. Elde edilen heyelan duyarlılık haritasının doğruluğu alıcı işletim karakteristik eğrisi ve eğri altında kalan alan ile değerlendirilmiş olup 0,84 olarak hesaplatılmıştır (Şekil 8). Bu değer kurulan modelin uyum iyiliğinin yüksek ve çok yüksek uyuma sahip olduğunu göstermektedir.

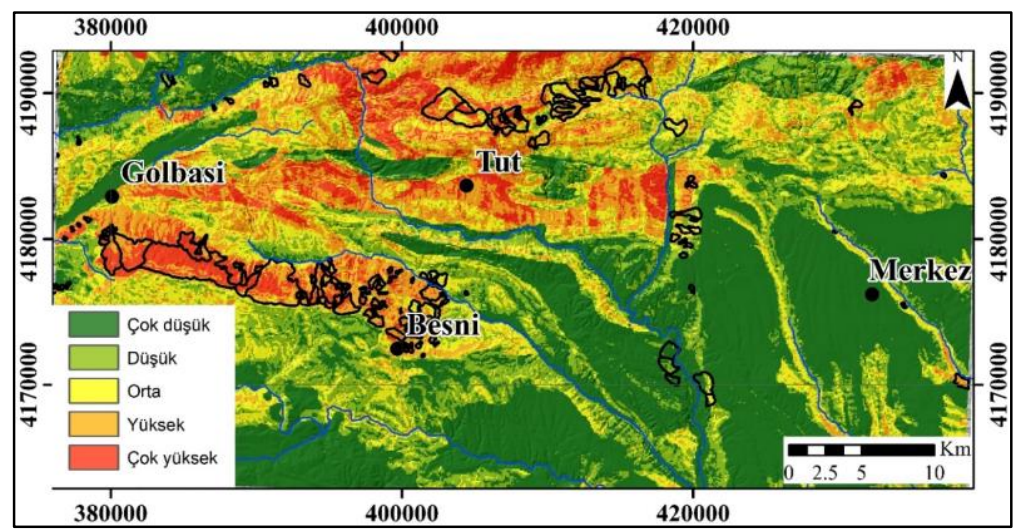

Şekil 7. Heyelan duyarlılık haritası
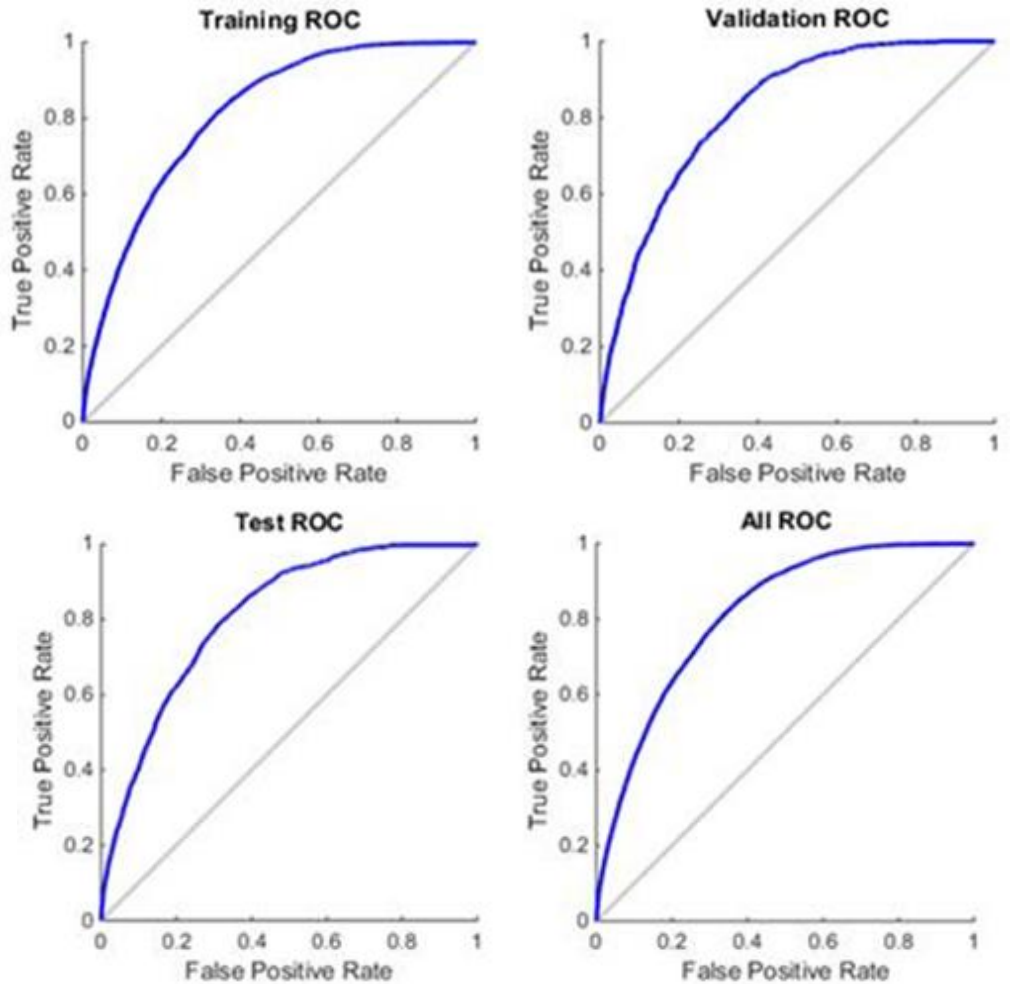

Şekil 8. Alıcı işletim karakteristik eğrileri 


\section{SONUÇLAR VE ÖNERİLER}

Adıyaman Gölbaşı-Adıyaman Merkez arasında kalan bölge için yapay sinir ağları yöntemi kullanılarak mekansal olabilirlik değerlendirmesi yapılmıştır. Çalışma sonucunda elde edilen heyelan duyarlılık haritasının güvenilirliği önceden gerçekleştiği bilinen heyelan envanterleri ile karşılaştırılarak kontrol edilmiştir. Elde edilen duyarlılık haritasına göre; çalışma alanının yaklaşık \%30'u heyelanların ise \%78,4'ü yüksek ve çok yüksek duyarlı alanlarda yer aldığ 1 gözlemlenmiştir. Çalışma alanının Gölbaşı (Adiyaman)-Besni (Adıyaman) arası ile Tut (Adıyaman) ve çevresinde heyelana duyarlı alanların yoğunlaştıği görülmüştür. Heyelan duyarlılığının yüksek olduğu bu alanlarda; heyelan ve heyelanla ilişkili olası tehlikeleri önlemeyi mümkün kılacak alanlar hakkındaki bilgilere 1 şık tutmakta. Yapılan çalışmanın sonuçları diğer meslek disiplinleri için de altlık oluşturmaktadır.

\section{KAYNAKLAR}

1. Lee, C.F., Li, J., Xu, Z. W., Dai, F.C., 2001. Assessment of Landslide Susceptibility on the Natural Terrain of Lantau Island, Hong Kong. Environmental Geology, 40(3), 381-391.

2. Çevik, E., Topal, T., 2003. GIS-based Landslide Susceptibility Mapping for a Problematic Segment of the Natural Gas Pipeline, Hendek (Turkey). Environmental Geology, 44(8), 949-962.

3. Scheuren, J.M., Le Polain, O., Below, R., Guha-Sapir, D., Ponserre, S., 2007. Annual Disaster Statistical Review. The Numbers and Trends, Proc. Annu. Hawaii Int. Conf. Syst. Sci., 2002 (Janua), 1060-1069.

4. Pradhan, B., 2010. Landslide Susceptibility Mapping of a Catchment Area Using Frequency Ratio, Fuzzy Logic and Multivariate Logistic Regression Approaches. Journal of the Indian Society of Remote Sensing, 38, 301-320.

5. Pradhan, B., Youssef, A.M., 2010. Manifestation of Remote Sensing Data and GIS on Landslide Hazard Analysis Using Spatial- based Statistical Models. Arabian Journal of Geosciences, 3, 319-326.

6. Bednarik, M., Yilmaz, I., Marschalko, M., 2012. Landslide Hazard and Risk Assessment: a Case Study from the HlohovecSered'landslide Area in South-west Slovakia. Natural hazards, 64, 547-575.

7. Devkota, K.C., Regmi, A.D., Pourghasemi, H.R., Yoshida, K., Pradhan, B., Ryu, I.C., Althuwaynee, O.F., 2013. Landslide Susceptibility Mapping Using Certainty Factor, Index of Entropy and Logistic Regression Models in GIS and Their Comparison at Mugling-narayanghat Road Section in Nepal Himalaya. Natural hazards, 65, 135-165.

8. Regmi, A.D., Devkota, K.C., Yoshida, K., Pradhan, B., Pourghasemi, H.R., Kumamoto, T., Akgun, A., 2014. Application of Frequency Ratio, Statistical Index, and Weights-ofevidence Models and Their Comparison in Landslide Susceptibility Mapping in Central Nepal Himalaya. Arabian Journal of Geosciences, 7, 725-742.

9. Tekin, S., Çan, T., 2019. Yapay Sinir Ağları Yöntemi ile Ermenek Havzası'nın (Karaman) Kayma Türü Heyelan Duyarlılık Değerlendirmesi. Bilge Int. J. Sci. Technol. Res., 3(1), 21-28.

10.Chu, H.J., Chen, Y.C., 2018. Crowdsourcing Photograph Locations for Debris Flow Hot Spot Mapping. Nat. Hazards, 90(3), 1259-1276.

11.Hu, W., Scaringi, G., Xu, Q., Huang, R., 2018. Internal Erosion Controls Failure and Runout of Loose Granular Deposits: Evidence From Flume Tests and Implications for Postseismic Slope Healing. Geophys. Res. Lett., 45(11), 5518-5527.

12.URL-1: https://www.mgm.gov.tr/, Erişim Tarihi: 01.02.2021.

13. Yildirim, N., Parlak, O., Robertson, A., 2012. Geochemistry and Tectonic Significance of the Koçali Ophiolite and the Related Koçali Melange, Adiyaman region, SE Turkey, $65^{\text {th }}$ Geological Congress of Turkey, 82-83.

14. Akbaş, B., Akdeniz, N., Aksay, A., Altun, İ.E., Balc1, V., Bilginer, E., Bilgiç, T., Duru, M., Ercan, T., Gedik, İ., Günay, Y., Güven, İ.H., Hakyemez, H.Y., Konak, N., Papak, İ., Pehlivan, Ş., Sevin, M., Şenel, M., Tarhan, N., 
Turhan, N., Türkecan, A., Ulu, Ü., Uğuz, M.F., Yurtsever, A., ve Diğerleri, 2011. 1:1.250.000 Ölçekli Türkiye Jeoloji Haritası. Maden Tetkik ve Arama Genel Müdürlüğü Yayını, AnkaraTürkiye.

15.Duman, Ö., Çan, T.Y., Emre, T., 2011. Türkiye Heyelan Envanteri Haritas1-1/1,500,000 Ölçekli, Maden Tetkik ve Arama Genel Müdürlüğü Özel Yayınlar Serisi, 27, 23.

16. Corominas, J., Van, Westen, C., Frattini, P., Cascini, L., Malet, J.P., Fotopoulou, S., Catani, F., Van Den Eeckhaut, M., Mavrouli, O., Agliardi, F., Pitilakis, K., Winter, M.G., Pastor, M., Ferlisi, S., Tofani, V., Hervás, J., Smith, J.T., 2014. Recommendations for the Quantitative Analysis of Landslide Risk. Bulletin of Engineering Geology and the Environment, 73(2), 209-263.

17. Kohonen, T., 1982. Self-organized Formation of Topologically Correct Feature Maps. Biol. Cybern., 43(1), 59-69.

18. Karsoliya, S., 2012. Approximating Number of Hidden Layer Neurons in Multiple Hidden Layer BPNN Architecture. Int. J. Eng. Trends Technol., 3(6), 714-717. 